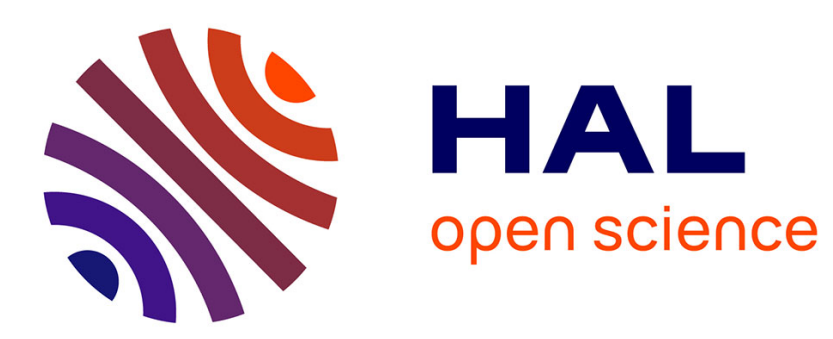

\title{
Endpoints in respiratory diseases
}

Fernando Maria Benedictis, Roberto Guidi, Silvia Carraro, Eugenio Baraldi

\section{To cite this version:}

Fernando Maria Benedictis, Roberto Guidi, Silvia Carraro, Eugenio Baraldi. Endpoints in respiratory diseases. European Journal of Clinical Pharmacology, 2010, 67 (S1), pp.49-59. 10.1007/s00228-0100922-2 . hal-00643849

\section{HAL Id: hal-00643849 \\ https://hal.science/hal-00643849}

Submitted on 23 Nov 2011

HAL is a multi-disciplinary open access archive for the deposit and dissemination of scientific research documents, whether they are published or not. The documents may come from teaching and research institutions in France or abroad, or from public or private research centers.
L'archive ouverte pluridisciplinaire HAL, est destinée au dépôt et à la diffusion de documents scientifiques de niveau recherche, publiés ou non, émanant des établissements d'enseignement et de recherche français ou étrangers, des laboratoires publics ou privés. 


\section{ENDPOINTS IN RESPIRATORY DISEASES}

-Part of TEDDY Supplement-

\section{Fernando Maria de Benedictis ${ }^{1}$, Roberto Guidi ${ }^{1}$, Silvia Carraro ${ }^{2}$, Eugenio Baraldi ${ }^{2}$ on behalf of the TEDDY European Network of Excellence}

${ }^{1}$ Dept of Pediatrics, Azienda Ospedaliero-Universitaria “Ospedali Riuniti”, Ancona, Italy

${ }^{2}$ Dept of Pediatrics, Unit of Allergy and Respiratory Medicine, University of Padova, Italy

Keywords: endpoints, outcome measures, respiratory

Word count: 4855

Corresponding author:

Prof. Eugenio Baraldi

Department of Pediatrics

Unit of Allergy and Respiratory Medicine

University of Padova

Via Giustiniani 3

35128 Padova - Italy

tel: 049-8213560

e-mail: baraldi@pediatria.unipd.it 


\section{Abstract}

A wide range of outcome measures or endpoints have been used in clinical trials to assess the effects of treatments in paediatric respiratory diseases. This can make difficult to compare treatment outcomes from different trials and also to understand whether new treatments offer a real clinical benefit for patients. Clinical trials in respiratory diseases evaluate three types of endpoints: subjective, objective and health-related outcomes. The ideal endpoint in a clinical trial needs to be accurate, precise and reliable. Ideally, the endpoint would also be measured with minimal risk and across all ages, easy to perform, and be inexpensive. Like for any other disease, endpoints for respiratory diseases must be viewed in the context of the important distinction between clinical endpoints and surrogate endpoints. The association between surrogate endpoints and clinical endpoints must be clearly defined for any disease, in order for them to be meaningful as outcome measures. The most common endpoints which are used in paediatric trials in respiratory diseases are discussed. For practical purposes, diseases have been separated into acute (bronchiolitis, acute viral-wheeze, acute asthma and croup) and chronic (asthma and cystic fibrosis). Further development of endpoints will enable clinical trials in children with respiratory diseases with the main objective of improving prognosis and safety. 


\section{INTRODUCTION}

Respiratory medicines for children are often used off-licence and off-label. ${ }^{1,2}$ An European Respiratory Society task force has recently reviewed the evidence for paediatric drugs in respiratory diseases, highlighting the need of robust endpoints for clinical trials in such field. ${ }^{3}$

A wide range of outcome measures or endpoints have been used in clinical trials to assess the effects of treatments in paediatric respiratory diseases. This can make difficult to compare treatment outcomes from different trials and also to understand whether new treatments offer a real clinical benefit for patients.

Generally, clinical trials in respiratory diseases evaluate three types of endpoints: subjective (i.e., symptom scores, need for rescue medication, quality-of-life measures), objective (i.e., lung function tests, markers of inflammation) and health-related outcomes (i.e., reduction in need for drugs, reduction in need for hospitalizations, reduction in absence from school, reduction in deaths). ${ }^{4}$

The ideal endpoint in a clinical trial needs to be accurate (to measure what it's purporting to measure), precise (to measure the underlying quality with minimal error and minimal variability), and reliable (a measurement made twice should produce the same results). Ideally, the endpoint would also be measured with minimal risk and across all ages, easy to perform, and be inexpensive.

Like for any other disease, endpoints for respiratory diseases must be viewed in the context of the important distinction between clinical endpoints and surrogate endpoints. ${ }^{5} \mathrm{Clinical}$ endpoints are defined as direct measures of how a patient feels, functions, or survives, and include resolution or prevention of symptoms. Clinical trial endpoints must be appropriate to the phase of the trial, the target population (in terms of disease severity and age), the duration of the study, the sample size, the number and expertise of participating sites, and, perhaps most importantly, the therapeutic aim (i.e. primary prevention, such as gene therapy, or secondary prevention, such as antibiotic or antinflammatory therapy). Surrogate endpoints, in contrast, are defined as laboratory measurements or physical signs that are used as a substitute for clinical endpoints, and include the remainder of our armamentarium, including lung function, culture results, and all imaging modalities. Surrogate endpoints must be biologically plausible, reflect clinical severity, be sufficiently sensitive, and correlate with true outcomes. ${ }^{6}$ Surrogate endpoints do not confer a direct clinical benefit to the patient and do not necessarily correlate with clinical endpoints. Therefore, the association between surrogate endpoints and clinical endpoints must be clearly defined for any disease, in order for them to be meaningful as outcome measures. In phase 1 and 2 trials, surrogate endpoints are an acceptable primary outcome, but in phase 3 trials, the U.S. Food and Drug Administration is increasingly requiring that the primary endpoint be a clinical endpoint (i.e., a measurement that demonstrates tangible benefit to the patient).

Here we discuss the most common endpoints which are used in paediatric trials designed to assess the efficacy of treatments in respiratory diseases. For practical purposes, diseases have been separated 
into acute and chronic. Among acute conditions, bronchiolitis, acute viral-wheeze, acute asthma and croup are considered. Asthma and cystic fibrosis are discussed as main example of chronic diseases. For acute conditions, the main endpoints may vary according with the type of protocol and the setting in which the evaluation is obtained (i.e. outpatient $v s$ inpatient evaluation). Safety is a particularly important outcome to address in paediatric trials, and should be assessed by separate endpoints in the acute setting or in long-term studies.

\section{BRONCHIOLITIS}

Bronchiolitis is the most common lower respiratory tract infection in the first year of life. Supportive care, including administration of oxygen and fluids, is the cornerstone of treatment. ${ }^{7}$

Most studies on bronchiolitis have examined only short-term endpoints, such as clinical scores (respiratory rate, retraction signs, and wheezing) or pulse oximetry. In hospitalized patients, a substantial effect on the length of the hospital stay and the time until the infant is ready for discharge would require a sustained clinical improvement. For that reason, the length of the hospital stay has been frequently selected as primary endpoint. However, since this outcome may be affected by many administrative and social factors unrelated to the condition of the child, another measure of efficacy the time until the patient is ready for discharge - has been assessed in several trials. The degree of change in respiratory rate, in heart rate and in clinical scores before and after therapy, and the time that supplemental oxygen is required are usually considered secondary outcomes. ${ }^{8}$ In some studies, the need for supplemental oxygen, based on the patient's oxygen saturation while breathing room air at admission, was highly predictive of the length of the hospital stay. Oxygen saturation measurements are usually performed in all infants admitted to the hospital with acute bronchiolitis and could therefore easily be used for planning appropriate staffing and bed requirements for paediatric wards. ${ }^{9}$

In children treated in emergency room (ER), the hospital admission within 7 days after the day of enrollment has been considered primary outcome. Recently, length and severity of symptoms after ER discharge evaluated by a standardized telephone follow-up procedure has been used as secondary endpoint. ${ }^{10}$

Differences in clinical definition of bronchiolitis exist between countries. Uniformity is needed to better differentiate infants with bronchiolitis from those with other illness, and to allow a comparison between studies performed in different parts of the world. Inpatient and outpatient studies should be considered separately. In inpatient studies, length of hospital stay is important, while in outpatient studies, prevention of admission should be the primary outcome. High quality clinical studies are still needed to clarify the value of different endpoints in the assessment of disease severity and criteria for hospital admission. ${ }^{11}$

\section{ACUTE VIRAL-INDUCED WHEEZE AND ACUTE ASTHMA}


Wheezing induced by respiratory viral infections is common in infants and preschool children. The optimal management of such children is controversial. This is mainly due to difficulties in stratification of treatment based on wheeze phenotype (i.e. episodic viral wheeze $v s$ multi-trigger wheeze).

The evidence for efficacy of treatments in acute viral wheeze falls broadly into two categories. First, lung function changes are "objective", but clinical relevance may be unclear. Secondly, there are studies using clinically relevant outcomes in acutely wheezy children. ${ }^{11}$

In recent studies in young children with acute viral wheeze, the duration of hospitalization was reported as primary endpoint. The time from enrolment to the time of actual discharge from the hospital, and the time from enrolment to the time that the patient was deemed to be "fit for discharge" (signoff for discharge) are frequently considered as distinct endpoints, since the time of actual discharge may be influenced by nonclinical factors. The total dose of inhaled albuterol during hospitalization, the mean 7-day symptom score (as assessed by a parent or guardian), the mean number of actuations of albuterol given at home during a 7-day period, the time required for the child to be "back to normal", and hospital readmission for wheezing within a month after discharge are usually considered secondary endpoints. ${ }^{12}$

Over the last few years, new more sophisticated endpoints have been used. The Preschool Respiratory Assessment Measure (PRAM) is a 12-point reproducible clinical scoring that captures clinical status in different parameters (scalene muscle contraction, suprasternal retractions, wheezing, air entry, and oxygen saturation). It has been validated against preschool lung function, ${ }^{13}$ and has a good internal consistency and reliability among raters. ${ }^{14}$ In addition, the severity of lower respiratory tract symptoms as reflected by the area under the curve for symptom scores in the 14-day interval after initiation of study medication has been also included between outcome measures. ${ }^{15}$

Acute asthma is a common, potentially life-threatening medical emergency and is responsible for a large number of ER visits and hospital admissions worldwide. Recently, an Italian Pediatric Society Task Force has graded the quality of evidence and the strength of recommendations for evaluation and treatment of acute asthma in children, with the aim of giving clear indications on the use of the drugs most employed in children. ${ }^{16}$ Suggestions on their limits due to unlicensed and off-label use are reported. The level of evidence and the strength of recommendations for different therapeutic approaches demonstrate that frequently the use of drugs in children is extrapolated from the experience in adults, and that more studies are required to endorse the correct use of medications in asthmatic children.

The administration of beta2-agonists represent the cornerstone for relieving bronchial obstruction in acute asthma. This aspect and relative recommendations for outcome measures in children with acute asthma have been recently tackled by a concise review (Tab. 1). ${ }^{17}$ 


\section{CROUP}

Viral croup is the most frequent cause of acute upper airway obstruction in children 6 months to 6 yrs of age. Croup symptoms are generally short-lived, the majority of children showing resolution within 2 days. ${ }^{22}$

Determination of disease severity of croup relies essentially on clinical assessment. Various proposed methods for objective assessment of respiratory distress in children with croup are either impractical or insensitive to change across the full range of disease severity. Consequently, in clinical trials of treatment effectiveness, outcome measures have mainly included clinical scores (i.e. Westley score) and health-care use. The time spent in ER, the number of return visits, hospital admissions, and in hospitalized children, the need for intubation and the risk of reintubation are other outcome measures that have been frequently considered in croup trials. Although such scores are useful for research studies, none has been shown to enhance routine clinical care, at least in part, because they are not reliable when used by a wide range of clinicians. ${ }^{23}$

\section{ASTHMA}

The assessment of asthma control is pivotal to the evaluation of treatment response in clinical trials. Previously, asthma control, severity, and exacerbations were defined in many different ways and the criteria used in their assessment have varied widely from study to study. This poses many drawbacks to make comparison between clinical trials and substantially limits the extent to which clinical trial data can be pooled for meta-analysis. An American Thoracic Society/European Respiratory Society Task Force on Asthma Control and Exacerbations was therefore established in order to provide recommendations about standardization of such outcomes in clinical trials and clinical practice, for adults and children aged 6 years or older. ${ }^{24}$ A summary of key points and recommendations, and specific paediatric issues for clinical trials are reported below.

\section{Asthma exacerbations}

Prevention of asthma exacerbations has been identified in all asthma guidelines as an important clinical outcome of ideal asthma control. Indeed, they constitute the greatest risk to patients, are a cause of anxiety to patients and their families, result in the greatest stress on health care providers, and generate the greatest cost to the health care system. Surprisingly, only in the past few years have exacerbations been used as a primary outcome variable in research trials to evaluate the efficacy of drug treatment in asthma.24 Exacerbations have been clearly defined by the ATS/ERS Task Force.

\section{Severe Asthma Exacerbations}


- Severe asthma exacerbations are events that require urgent action on the part of the patient and physician to prevent a serious outcome, such as hospitalization or death from asthma. The occurrence of severe asthma exacerbations should be used as a marker of poor asthma control.

- The definition of a severe asthma exacerbation for clinical trials should include at least one of the following: i) use of systemic corticosteroids, or an increase from a stable maintenance dose, for at least 3 days. Courses of corticosteroids separated by 1 week or more should be treated as separate severe exacerbations. ii) A hospitalization or ER visit because of asthma, requiring systemic corticosteroids.

- The inclusion of a percentage change in PEF from baseline is not currently recommended as a criterion for severe exacerbations.

- There are currently no validated criteria for the magnitude of change in symptoms and/or beta2agonist use that define a severe asthma exacerbation. If included in a study, changes in PEF, symptoms, and/or beta2-agonist use should persist for 2 or more days (unless very severe) to qualify as a severe exacerbation.

\section{Moderate Asthma Exacerbations}

- A moderate asthma exacerbation is an event that should result in a temporary change in treatment, in an effort to prevent the exacerbation from becoming severe.

- The definition of a moderate asthma exacerbation should include one or more of the following: i) deterioration in symptoms; ii) deterioration in lung function; iii) increased rescue bronchodilator use. These features should last for 2 days or more, but not be severe enough to warrant systemic corticosteroid use and/or hospitalization. ER visits for asthma not requiring systemic corticosteroids may be classified as moderate exacerbations.

\section{Mild Asthma Exacerbations}

A definition of a mild asthma exacerbation is not justifiable with present methods of analysis, because the symptoms or changes in flow rates during these episodes will be only just outside the normal range of variation for the individual patient and may reflect transient loss of asthma control rather than the early stages of a severe exacerbation.

\section{Paediatric issues}

- In young children with asthma, exacerbations are frequent, with significant morbidity, possibly because of the frequency of viral infections.

- There are no reliable methods for early detection, but the development of upper airway symptoms of viral infection may be a useful alert. 
- The severity of exacerbations is also difficult to characterize in children, because of dependence on parental reporting of symptoms and the difficulty of measuring lung function.

\section{Asthma Control}

Asthma control is defined as the extent to which the various manifestations of asthma have been reduced or removed by treatment. This includes two components:

1. The level of clinical asthma control, which is gauged from features such as symptoms and the extent to which the patient can carry out activities of daily living.

2. The risk of future adverse events including loss of control, exacerbations, accelerated decline in lung function, and side-effects of treatment.

Given that the goals of asthma treatment relate to both the achievement of good control and the minimization of future risk, it is not appropriate to specify a single primary endpoint for the assessment of asthma control. Studies of clinical efficacy and effectiveness should use appropriate endpoints which capture both aspects of asthma control.

The four components of the definition of asthma (symptoms, airway obstruction, airway hyperresponsiveness, and airway inflammation) are only loosely associated, ${ }^{26}$ so no one of these domains is completely suitable as a comparator for validation of individual measures of asthma control. The primary perspective for the assessment of asthma control is that of the patient. However, the level of control that may be acceptable to one patient may be unacceptable to another or to a clinician. In each case, patient-reported measures should be supplemented by the objective measures that relate to the pathophysiologic domains of the definition of asthma.

\section{a) Diary data}

Symptoms and airway obstruction are integral to the definition of asthma and represent important components of the assessment of asthma control in clinical trials. There are many limitations to the use of diary data in asthma trials, which can be partially overcome by the correct selection of the variables and by application of appropriate statistical methods.

- Diaries are useful to assess asthma control in any clinical trial and for patient characterization before randomization, to avoid the problems of patient recall and the effects of change in medication adherence.

- Electronic diaries should be preferred to paper diaries to improve data quality.

- The use of standardized diaries that have been formally validated in an appropriate population of individuals with asthma (mild or severe, adult or paediatric, self-completed or caregivercompleted) should be promoted.

- Diaries should include questions on asthma symptoms, night-waking due to asthma, and reliever use. 
- "Symptom-free days" is a useful diary variable, but may not be sufficiently responsive in study populations with either very frequent or infrequent symptoms.

- Ambulatory recording of lung function (FEV1 and/or PEF) is used in some studies to provide information complementary to that provided by symptom diaries. Mean morning PEF provides information about current clinical control, and peak flow variability provides independent information about risk of future exacerbations.

- Diary data should be collected and analyzed over the whole treatment period to capture asthma control over a longer interval.

\section{Paediatric issues}

- Paediatric studies should use diaries specifically validated for this age group.

- For children less than 12 years of age, diary completion by caregiver rather than child may result in a more complete dataset, but may introduce bias.

- Ambulatory lung function monitoring has little role in studies in children.

\section{b) Lung function and airway hyperresponsiveness (AHR)}

Spirometry is an objective and well-standardized measure of airflow limitation. It can give important information to the physician as measure of asthma control.

\section{Spirometry}

- The relative importance of spirometry among the endpoints in clinical trials depends on the study objectives.

- Spirometry, as measured by pre-bronchodilator FEV1, is one of the fundamental objective measures of asthma control and is a strong independent predictor of future risk of exacerbations.

- FEV1 should be included as a primary endpoint for studies of bronchodilator therapy. FEV1 is highly responsive to the successful relief of bronchoconstriction over the entire range of asthma severity, except for those with normal baseline lung function.

- Post-bronchodilator FEV1 is recommended in studies of long-term decline in lung function and airway wall remodeling.

\section{Airway Hyperresponsiveness}

- AHR should be regarded as an integrative disease marker, reflecting multiple pathophysiologic mechanisms.

- Where possible, AHR should be included in clinical trials at baseline to characterize the study population. 
- AHR is a desirable outcome in studies focusing on modification of underlying disease activity. Direct or indirect challenge agents can be used, according with the type of the study and the specific outcome requested.

- AHR can be used as a predictor of future risk of exacerbations and decline in lung function in longitudinal studies of childhood and adult asthma.

\section{Paediatric issues}

- In children, measuring spirometry is important not only for assessing asthma control, but also for assessing lung development over time.

- Spirometry can be routinely measured in children aged approximately 6 years and older. However, with appropriate training, preschool children may be able to perform spirometry.

- Young children have difficulty performing the 6-second forced expiratory maneuver recommended for spirometry in adults. Therefore, shorter expiratory times may be acceptable if reproducible.

- Forced oscillation procedures and interrupter resistance (Rint) to measure airways resistance can be applied in children as young as 3 years of age.

\section{c) Composite scores}

The concept of composite measures for interval assessments of asthma control is based on three facts: the generally poor correlation between different domains of asthma, the absence of a single "gold standard" for the measurement of asthma control, and evidence that a composite measure comprising different endpoints provides a more complete picture of asthma control than any single endpoint. . $^{27,28,29}$ The use of composite measures in clinical trials enables numeric comparisons of treatment effects to be made. Over the last few years, considerable progress has been made in validating these instruments for research and clinical use.

- Composite scores have the potential to be used as primary or co-primary endpoints in clinical trials.

- Composite scores should be relatively simple and easy to administer. They must be suitable for a full range of patients and modified to suit different patient groups (e.g., children).

- Composite measures that record asthma control as a simple numeric form should be favoured.

- Categorical composite measures do not necessarily provide a full picture of asthma control, particularly with regard to future risk.

\section{Paediatric issues}


- Assessment of asthma control in children is usually based on parent reports. The reliability of symptom assessment from questionnaires may be influenced by poor symptom perception and reporting by the child or by the parents.

- Symptom-free days is a useful endpoint for paediatric asthma studies and easier to record than symptom scores.

- Since the decision to take rescue bronchodilator is often made by the parents, this indicator may not assess asthma control accurately in young children.

- Some age-specific paediatric versions of commonly used control questionnaires, validated in different languages, are becoming available for clinical studies (e.g., ATAQ, ACT). However, their potential application in paediatric clinical practice needs to be carefully evaluated.

\section{d) Biomarkers of airway inflammation}

Over the last 15 years there has been increasing interest in the noninvasive assessment of airway inflammation as an adjunct to the assessment of clinical asthma control. ${ }^{30} \mathrm{~A}$ number of candidate measures have been developed and validated. ${ }^{31,32,33,34}$

\section{Induced Sputum}

- Sputum induction is feasible and safe, and the induction and processing techniques have been well validated.

- Assessment of eosinophilic airway inflammation using induced sputum provides additional, clinically important information about inhaled corticosteroids responsiveness and preventable future risk of exacerbations.

- Minimization of eosinophilic airway inflammation should be considered as an additional criterion for control of the underlying disease activity and for reduction of future risk, especially in patients with more severe asthma.

\section{Fraction of exhaled nitric oxide (FENO)}

- FENO measurements provide easily obtained information on underlying disease activity where it is characterized by eosinophilic airway inflammation.

- FENO does not provide information about other types of airway inflammation, and this may be a problem in more severe asthma, where neutrophilic inflammation may be more important.

- The clinical utility of FENO-based management strategies has not been explored extensively. Currently available evidence suggests a role in identifying the phenotype in airways disease, particularly in the identification of corticosteroid responsiveness.

- Due to logistic and cost issues, FENO is the only biomarker likely to have a role in primary carebased asthma studies. 


\section{Exhaled breath condensate (EBC)}

Many markers of airway inflammation have been reported in EBC. The most commonly reported markers include those that indicate oxidative stress such as 8-isoprostane and hydrogen peroxide, as well as the leukotrienes and airway $\mathrm{pH}$. More work is needed on the validation of the various measures from EBC and to describe the relationship between these measures and other markers of asthma control.

\section{Serum eosinophil cationic protein (ECP)}

A standardized collection, processing, and testing method has been described for ECP. Compared with eosinophil counts, ECP measurements in either induced sputum or serum fail to reflect treatmentrelated changes in chronic asthma, suggesting that serum ECP is not a sensitive or reliable means of evaluating eosinophilic airway inflammation.

\section{Paediatric issues}

- Experience with biomarkers in childhood asthma is limited, but they could be useful in making an asthma diagnosis and for selecting appropriate medications based on phenotype.

- FENO is a prototype for the application of biomarkers in children with asthma, and may be helpful in decisions on starting and stopping inhaled corticosteroids, and perhaps monitoring medication effects.

- Successful sputum induction in children is limited to those children 8 years and older. Serial assessment of sputum may be problematic, as many children are unwilling to undergo repeat sputum inductions.

\section{e) Indirect measures of asthma control}

Loss of asthma control potentially leads to unscheduled use of health care, loss of work and school productivity or absenteism, and need for additional medication. Measures of health care utilization provide surrogate measures for asthma control, which are particularly useful when direct clinical measures are not available.

- Only unscheduled consultations serve as a marker of poor asthma control. They should be defined as those initiated by the patient because of worsening asthma.

- Data should be collected from standardized physician-completed forms at the time of patient contact. Telephone consultations and nurse consultations should be reported separately.

- Systemic corticosteroid usage is an outcome marker of control and should be recorded as the total number of courses per patient per year.

\section{f) Health-related quality of life (HRQOL)}


Quality of life (QOL) has been defined as "the functional effects of an illness and its consequent therapy upon a patient, as perceived by the patient". ${ }^{35}$ It includes somatic sensation (the problems associated with symptoms), physical and occupational function, emotional and psychological impact, and social interaction. HRQOL can be considered as the component related to the overall burden of a chronic disease with respect to these domains.

At present, the role of HRQOL assessment in clinical trials is linked to the willingness of the study sponsor to incorporate such measures into the process of drug development. Regulatory agencies such as EMEA and FDA have shown interest in patient-reported outcomes and specifically in HRQOL, and the FDA has provided draft guidelines to facilitate the development of robust questionnaires and to better understand the information obtained from HRQOL.

HRQOL questionnaires measure the impact of asthma on the individual, and provide complementary rather than direct information about asthma control or severity. Several HRQOL instruments have been developed and validated.

- HRQOL should be used as a specific assessment tool in asthma clinical trials.

- To correctly interpret changes in HRQOL, proper outcomes should be defined for each validated HRQOL measure.

- Potential gains in HRQOL resulting from treatment may be offset by the impact of drug-related side effects or co-morbidities.

- The effect of cultural and educational differences on HRQOL assessment should be considered in the development and use of questionnaires.

\section{Paediatric issues}

- All disease-specific QOL instruments used for paediatric studies should be validated for relevant age groups.

- The Pediatric Asthma Quality of Life Questionnaire (PAQLQ) is a paediatric disease-specific QOL instrument designed and validated in several languages for children aged 6 to 18 years. An asthma-related QOL questionnaire for caregivers has been developed by the same authors.

- For any paediatric QOL instrument, the study protocol should specify whether the carer or the child should answer the QOL measure.

- Child-completed QOL questionnaires must take into consideration the child's reading level. Children under 12 years of age may have difficulty reading or understanding a questionnaire without assistance.

- When children are assisted by their parent in completing a questionnaire, their responses change. Therefore, child completed questionnaires should either be completed by the child alone or with the assistance of professional staff, as specified in the protocol for that test. 


\section{Choice of endpoints}

In asthma, some outcome measures provide information about current clinical control, some about future risk, and some about both. Hence, it is not appropriate to recommend a single endpoint for the assessment of asthma control. In long-term therapeutic studies, the effect of the intervention on some future risks (i.e., exacerbations) may be measured directly. However, it is impractical for all studies to be of sufficient duration to directly measure these events, so, in shorter studies, inferences about some future risks may be drawn from measurement of biomarkers and physiologic measures. For any study, the choice of the main endpoints may vary according to the specific intervention requested. A list of the outcome measures for asthma control together with their relative importance (essential, desirable, or optional) is shown in Tab. 2.

\section{CYSTIC FIBROSIS}

Cystic fibrosis (CF) is a common inherited disease with a median life expectancy that has changed significantly, within a period of three decades, approximately from 10 years to 40 years. This favorable result has been achieved through research, the development of adequate therapeutic and prophylactic medications, the treatment by multidisciplinary CF teams, and through early intervention for patients with pulmonary disease. ${ }^{36,37}$

The most common endpoints used in CF trials are quality-of-life evaluated by questionnaires, pulmonary exacerbation rate, lung function, growth, microbiology, inflammatory markers, nasal potential difference, and imaging studies. The large target age population may affect the choice of endpoints in studies on CF. In a recent study that evaluated the effect of inhaled hypertonic saline in patients who were at least 6 years old, the linear rate of change in lung function was considered as primary endpoint. ${ }^{38}$ The level of lung function during treatment, the incidence of pulmonary exacerbations, the time free of pulmonary exacerbations, antibiotic use, the number of days on which patients could not participate in their usual activities, results of quantitative microbiologic analyses, the body-mass index, and the quality of life were considered as secondary endpoints. Critical aspects of endpoints for CF clinical trials have been recently reviewed. ${ }^{39}$

In children with CF under 6 years of age, the endpoints are particularly limited. Young children cannot cooperate with spirometry, and their lung disease is generally mild, so that lung function and imaging studies are relatively insensitive. Furthermore, young children cannot expectorate sputum or cooperate with sputum induction, so respiratory cultures either have to be obtained by oropharyngeal swab, which has relatively poor diagnostic accuracy compared with lower airway cultures, or by bronchoalveolar lavage, which is invasive ${ }^{39}$ Similarly, a standardized questionnaire for patients with CF (Cystic Fibrosis Quality-of-Life Questionnaire) is not available for children under 6 years of age. ${ }^{40}$

A recent review on endpoints for CF clinical trials has highlighted methodology, clinical and biologic relevance, sensitivity and specificity to treatment, feasibility, and safety for each potential 
endpoint in young children with CF. ${ }^{41}$ In these patients, endpoints include infant and preschool lung function testing, computed tomography of the chest, bronchoalveolar lavage, and pulmonary exacerbations. During the next 10 years, intervention trials in the youngest $\mathrm{CF}$ population using physiologic, anatomic, bronchoscopic and clinical endpoints will likely lead to improved outcomes due to the identification and treatment of early lung disease. ${ }^{41}$ A summary of endpoints for CF clinical trials, and future directions of outcome measures in young children with CF are shown in Tab. 3 and 4, respectively. 


\section{References}

1. Bush A (2006) Evidence-based medicines for children: important implications for new therapies at all ages. Eur Respir J 28:1069-1072

2. Baiardi P, Ceci A, Felisi M, Cantarutti L, Girotto S, Sturkenboom M, Baraldi E (2010). In-label and off-label use of respiratory drugs in the Italian paediatric population. Acta Paediatr Jan 27. [Epub ahead of print]

3. Smyth AR, Barbato A, Beydon N, Bisgaard H, de Boeck K, Brand P, et al (2010) Respiratory medicines for children: current evidence, unlicensed use and research priorities. Eur Respir J $35: 247-265$

4. Spahn J (2003) Clinical trial efficacy: what does it really tell you? J Allergy Clin Immunol 112:S102-S106

5. Biomarkers Definitions Working Group (2001) Biomarkers and surrogate endpoints: preferred definitions and conceptual framework. Clin Pharmacol Ther 69:89-95

6. Prentice RL (1989). Surrogate endpoints in clinical trials: definition and operational criteria. Stat Med;8:431-440

7. Smyth RL, Openshaw PJ (2006) Bronchiolitis. Lancet 368:312-322

8. Wainwright C, Altamirano L, Cheney M, Cheney J, Barber S, Price D, et al (2003) A multicenter, randomized, double-blind, controlled trial of nebulized epinephrine in infants with acute bronchiolitis. N Engl J Med 349:27-35

9. Gajdos V, Beydon N, Bommenel L, Pellegrino B, de Pontual L, Bailleux S, et al (2009) Interobserver agreement between physicians, nurses, and respiratory therapists for respiratory clinical evaluation in bronchiolitis. Pediatr Pulmonol 44:754-762

10. Plint AC, Johnson DW, Patel H, Wiebe N, Correll R, Brant R, et al (2009) Epinephrine and dexamethasone in children with bronchiolitis. N Engl J Med 360:2079-2089

11. Lenney W, Boner AL, Bont L, Bush A, Carlsen KH, Eber E, et al (2009) Medicines for children used in respiratory diseases only seen in children. Eur Resp J 34:531-551

12. Panickar J, Lakhanpaul M, Lambert PC, Kenia P, Stephenson T, Smyth A, Grigg J (2009) Oral prednisolone for preschool children with acute virus-induced wheezing. N Engl J Med 360:329338

13. Chalut DS, Ducharme FM, Davis GM (2000) The Preschool Respiratory Assessment Measure (PRAM): a responsive index of acute asthma severity. J Pediatr 137:762-768

14. Ducharme FM, Chalut D, Plotnick L, Savdie C, Kudirka D, Zhang X, et al (2008) The Pediatric Respiratory Assessment Measure: a valid clinical score for assessing acute asthma severity from toddlers to teenagers. J Pediatr 152:476-480 
15. Bacharier LB, Phillips BR, Zeiger RS, Szefler SJ, Martinez FD, Lemanske RF, et al (2008) Episodic use of an inhaled corticosteroid or leukotriene receptor antagonist in preschool children with moderate-to-severe intermittent wheezing. J Allergy Clin Immunol 122:1127-1135

16. Indinnimeo L, Bertuola F, Cutrera R, de Benedictis FM, Di Pietro P, Duse M, et al (2009) Clinical evaluation and treatment of acute asthma exacerbations in children. Int J Immunopathol Pharmacol 22:867-878

17. Ferguson C, Gidwani S (2006) Best evidence topic reports. Delivery of bronchodilators in acute asthma in children. Emerg Med J 23:471-472

18. Schuh S, Johnson DW, Stephens D, Callahan S, Winders P, Canny GJ (1999) Comparison of albuterol delivered by a metered dose inhaler with a spacer versus a nebulizer in children with mild acute asthma. J Pediatr 135;22-27

19. Cates CJ, Bara A, Crilly JA, Rowe BH (2003) Holding chambers versus nebulisers for betaagonist treatment of acute asthma. Cochrane Database Syst Rev: CD000052. Review. Update in: Cochrane Database Syst Rev 2006;(2):CD000052

20. Castro-Rodriguez JA, Rodrigo GJ (2004) Beta-agonists through metered-dose inhaler with valved holding chamber versus nebulizer for acute exacerbations of wheezing or asthma in children under 5 years of age; a systematic review with metanalysis. J Pediatr 145:172-177

21. Deerojanawong J, Manuyakorn W, Prapphal N, Harnruthakorn C, Sritippayawan S, Samransamruajkit R (2005) Randomized controlled trial of salbutamol aerosol therapy via metered dose inhaler-spacer vs. jet nebulizer in young children with wheezing. Pediatr Pulmonol 39:466472

22. Cherry JD (2008) Croup. N Engl J Med 358:384-391

23. Bjornson CL, Johnson DW (2008) Croup. Lancet 371:329-339

24. Reddel HK, Taylor DR, Bateman ED, Boulet LP, Boushey HA, Busse WW, et al (2009) American Thoracic Society/European Respiratory Society Task Force on Asthma Control and Exacerbations. An official American Thoracic Society/European Respiratory Society statement: asthma control and exacerbations: standardizing endpoints for clinical asthma trials and clinical practice. Am $\mathbf{J}$ Respir Crit Care Med 180:59-99

25. Pauwels RA, Lofdahl C-G, Postma DS, Tattersfield AE, O’Byrne P, Barnes PJ, Ullman A (1997) Effect of inhaled formoterol and budesonide on exacerbations of asthma. N Engl J Med 337:14051411

26. Kerstjens HAM, Brand PLP, Jong PMD, Koeter GH, Postma DS, for the Dutch CNSLD Study Group (1994) Influence of treatment on peak expiratory flow and its relation to airway hyperresponsiveness and symptoms. Thorax 49:1109-1115

27. Juniper EF, O'Byrne PM, Guyatt GH, Ferrie PJ, King DR (1999) Development and validation of a questionnaire to measure asthma control. Eur Respir J 14:902-907 
28. Cockcroft DW, Swystun VA (1996) Asthma control versus asthma severity. J Allergy Clin Immunol 98:1016-1018

29. Nathan RA, Sorkness CA, Kosinski M, Schatz M, Li JT, Marcus P, et al (2004) Development of the asthma control test: a survey for assessing asthma control. J Allergy Clin Immunol 113:59-65

30. Scichilone N, Deykin A, Pizzichini E, Bellia V, Polosa R (2004) Monitoring response to treatment in asthma management: food for thought. Clin Exp Allergy 34:1168-1177

31. Covar RA, Spahn JD, Martin RJ, Silkoff PE, Sundstrom DA, Murphy J, Szefler SJ (2004) Safety and application of induced sputum analysis in childhood asthma. J Allergy Clin Immunol 114:575582

32. American Thoracic Society; European Respiratory Society (2005) ATS/ERS Recommendations for standardized procedures for the online and offline measurement of exhaled lower respiratory nitric oxide and nasal nitric oxide, 2005. Am J Respir Crit Care Med 171:912-930

33. Horvath I, Hunt J, Barnes PJ, Alving K, Antczak A, Baraldi E, et al (2005) Exhaled breath condensate: methodological recommendations and unresolved questions. Eur Respir J 26:523-548

34. Venge P, Bystrom J, Carlson M, Hakansson L, Karawacjzyk M, Peterson C, et al (1999) Eosinophil cationic protein (ECP): molecular and biological properties and the use of ECP as a marker of eosinophil activation in disease. Clin Exp Allergy 29:1172-1186

35. Erickson SR, Kirking DM (2004) Variation in the distribution of patient reported outcomes based on different definitions of defining asthma severity. Curr Med Res Opin 20:1863-1872

36. Rowe SM, Miller S, Sorscher EJ (2005) Cystic Fibrosis. N Engl J Med 352:1992-2001

37. O'Sullivan BP, Freedman SD (2009) Cystic fibrosis. The Lancet 373:1891-1904

38. Elkins MR, Robinson M, Rose BR, Harbour C, Moriarty CP, Marks GB, et al (2006) A controlled trial of long-term inhaled hypertonic saline in patients with cystic fibrosis. N Engl J Med 354:229240

39. Rosenfeld M (2007) An overview of endpoints for cystic fibrosis clinical trials: one size does not fit all. Proc Am Thor Soc 4:299-301

40. Quittner AL, Sweeny S, Watrous M, Munzenberger P, Bearss K, Gibson Nitza A, et al (2000) Translation and linguistic validation of a disease-specific quality of life measure for cystic fibrosis. J Pediatr Psychol 25:403-414

41. Davis SD, Brody AS, Emond MJ, Brumback LC, Rosenfeld M (2007) Endpoints for clinical trials in young children with cystic fibrosis. Proc Am Thorac Soc 4:418-430 
TABLE 1

Outcomes measures in children with acute asthma

\begin{tabular}{|c|c|c|c|}
\hline Author & Study type & Patient group and setting & Outcomes \\
\hline Schuh $^{17}$ & Single-dose, DBRCT & $\begin{array}{l}90 \text { children, } 5 \text { to } 17 \text { years } \\
\text { Emergency room }\end{array}$ & $\begin{array}{l}\text { Difference of percentage change in } \mathrm{FEV}_{1} \\
\text { Admission rate } \\
\text { Heart rate following treatment } \\
\text { Relapse requiring unscheduled medical visit }\end{array}$ \\
\hline Cates $^{18}$ & Systematic review of $28 \mathrm{DBRCT}$ & $\begin{array}{l}1076 \text { children (not infants) } \\
\text { Emergency room }\end{array}$ & $\begin{array}{l}\text { Hospital admission rate } \\
\text { Time spent in the emergency room } \\
\mathrm{PEF} \text { and } \mathrm{FEV}_{1} \text { at } 30 \text { min and end of the study } \\
\text { Pulse rate }\end{array}$ \\
\hline Castro-Rodriguez $^{19}$ & $\begin{array}{l}\text { Systematic review of } 6 \text { DBRCT } \\
\text { with meta-analysis }\end{array}$ & $\begin{array}{l}491 \text { children, } 1 \text { to } 60 \text { months } \\
\text { Emergency room }\end{array}$ & $\begin{array}{l}\text { Admission rate } \\
\text { Clinical severity score }\end{array}$ \\
\hline Deerojanawong $^{20}$ & Prospective, RDBCT & $\begin{array}{l}47 \text { children under } 5 \text { years } \\
\text { Inpatients }\end{array}$ & $\begin{array}{l}\text { Change in ratio of VPTEF against TPTEF } \\
\text { Reduction in resistance of respiratory system } \\
\text { Change in heart rate }\end{array}$ \\
\hline
\end{tabular}

Definition of abbreviations: DBRCT $=$ double blind, randomized, controlled trial; $\mathrm{FEV}_{1}=$ Forced Expiratory Volume in 1 second; PEF $=$ Peak Expiratory Flow $\mathrm{VPTEF}=$ Volume to Peak Tidal Expiratory Flow; TPTEF $=$ Time to Peak Tidal Expiratory Flow 
TABLE 2

Recommended outcome measures relating to asthma control for clinical trials

Essential Desirable Optional

1. Baseline characteristics

$\begin{array}{ll}\text { Symptom-free days } & \text { Diary data } \\ \text { Reliever use } & \text { Airway hyperresponsiveness } \\ \text { Pre-BD FEV } & \text { Biomarkers } \\ \text { Post-BD FEV }_{1} & \text { Treatment side-effects } \\ \text { Composite scores } & \text { History of exacerbations } \\ \text { Quality of life } & \end{array}$

On-treatment $\mathrm{FEV}_{1}$

2. Outcome measures for the assessment of treatment effect

. . on current clinical control

Symptom-free days
Reliever use
Composite scores
Exacerbation
Quality of life

On-treatment FEV 1 Diary data Indirect measures
Biomarkers Airway hyperresponsiveness Post-BD FEV $_{1}$

. . on future risk

For direct measurement of
adverse outcomes
Exacerbations
Post-BD FEV $_{1}$
Composite scores
For indirect assessment of risk
of adverse outcomes
Pre-BD FEV
(as predictor for exacerbations)
For direct measurement of adverse outcomes
Diary data
Health care utilization
Treatment side-effects
For indirect assessment of risk
of adverse outcomes
Airway hyperresponsiveness
(as predictor of future risk)
Biomarkers (as predictor of future risk)

Definition of abbreviations: $\mathrm{BD}=$ bronchodilator; $\mathrm{FEV}_{1}=$ Forced Expiratory Volume in 1 second 


\section{TABLE 3}

Summary of cystic fibrosis clinical trial endpoints

\begin{tabular}{|c|c|c|c|c|c|c|}
\hline Endpoint & Age (yr) & Risk & Expense & Standardized? & Advantages & Disadvantages \\
\hline $\begin{array}{l}\text { Pulmonary } \\
\text { exacerbation }\end{array}$ & All ages & Minimal & Low & $\begin{array}{l}\text { No standardized } \\
\text { definition }\end{array}$ & $\begin{array}{l}\text { Clinical endpoint } \\
\text { Responsive to } \\
\text { interventions }\end{array}$ & $\begin{array}{l}\text { No standardized definition } \\
\text { Relatively rare event } \\
\text { in young children }\end{array}$ \\
\hline Quality of life & $>6$ & Minimal & Low & Yes & $\begin{array}{l}\text { Clinical endpoint } \\
\text { Validated instrument }\end{array}$ & $\begin{array}{l}\text { Responsiveness to } \\
\text { interventions not established }\end{array}$ \\
\hline Spirometry & $>6$ & Minimal & Low & Yes & $\begin{array}{l}\text { Widely used endpoint } \\
\text { Epidemiological data } \\
\text { linking to survival }\end{array}$ & $\begin{array}{l}\text { Insensitive to early disease } \\
\text { High variability }\end{array}$ \\
\hline Infant lung function & $>3$ & Greater than & Moderate-high & Yes & $\begin{array}{l}\text { Allows assessment } \\
\text { of early lung disease }\end{array}$ & $\begin{array}{l}\text { Insensitive to early disease } \\
\text { Expensive equipment }\end{array}$ \\
\hline Chest radiograph & All ages & Minimal & Low & $\begin{array}{l}\text { Several widely accepted } \\
\text { scoring systems }\end{array}$ & Simple, inexpensive & Insensitive to early disease \\
\hline $\begin{array}{l}\text { Chest computed } \\
\text { tomography }\end{array}$ & All ages & $\begin{array}{l}\text { Greater than } \\
\text { minimal }\end{array}$ & Moderate-high & $\begin{array}{l}\text { Poor agreement on } \\
\text { scoring }\end{array}$ & $\begin{array}{l}\text { Measured across all ages } \\
\text { Sensitive to mild disease } \\
\text { Assesses structure and } \\
\quad \text { regional disease }\end{array}$ & $\begin{array}{l}\text { Responsiveness not well } \\
\quad \text { established } \\
\text { Radiation, sedation, cost } \\
\text { Lack of standardized approach }\end{array}$ \\
\hline Respiratory cultures & All ages & Minimal & Low-moderate & Yes & $\begin{array}{l}\text { Assessment of respiratory } \\
\text { pathogens }\end{array}$ & $\begin{array}{l}\text { In preexpectoring patients, } \\
\text { poor sensitivity of } \\
\text { oropharyngeal cultures }\end{array}$ \\
\hline
\end{tabular}

Modified from ref. 38 
TABLE 4

Future directions of outcome measures in young children with cystic fibrosis

Outcome measure

Infant lung function testing

Preschool lung function testing

Chest computed tomography

Bronchoalveolar lavage

Pulmonary exacerbations

\section{Future directions}

1. Use as endpoint in multicenter trial (RVRTC technique, plethysmography)

2. Define measures that are most responsive to different types of interventions

1. Standardization of techniques, equipment, and software

2. Use several measures as secondary endpoints in a clinical trial

3. Evaluate response of lung clearance index to an intervention

1. Standardize scoring system for use in infants and young children

2. Standardize the controlled breathing technique

3. Standard guidelines for minimizing radiation exposure

4. Better define natural history of the disease

5. Standardize operating procedures for multicenter trials

6. Use as exploratory endpoint in clinical trial

1. Standardize methods for multicenter trials

1. Development of a standardized definition

2. Use as a clinical trial endpoint

Definition of abbreviation: RVRTC = raised volume rapid thoracoabdominal compression

Modified from ref. 40 